\title{
Relation of the graphite and fluid bearing conducting dikes to the tectonics and seismicity (Review on the Transdanubian crustal conductivity anomaly)
}

\author{
Antal Ádám \\ Geodetic and Geophysical Research Institute (GGRI), H-9401 Sopron, POB 5, Hungary
}

(Received December 5, 2000; Revised May 25, 2001; Accepted May 28, 2001)

\begin{abstract}
Two Hungarian geophysical institutes (GGRI, ELGI) carried out about 300 magnetotelluric (MT) deep soundings in the NW part of Transdanubia (W-Hungary) partly along basic profiles, partly in areal distribution. These measurements aimed first of all at the determination of the tectonic structures represented by a strong conductivity anomaly (CA) detected in the early 1960's in the upper crust. The analysis of the conductivity anomaly has been made by successive approximation i.e. by pseudosections, $1 \mathrm{D}$ inversion and $2 \mathrm{D}$ inversion. For the 2D inversion the regional strike direction has been determined by the rose diagram of the Groom-Bailey decomposition strikes, by electromagnetic (EM) distortion analysis and by "phase maps" and found that the regional strike-direction is NE-SW. Using different 2D inversion techniques, the tectonic structure of the presumably Paleozoic graphite and fluid containing conductors representing almost parallel strike slips, shear zones and the thrust sheets, etc. have been determined. The low viscosity graphite and/or fluid could be smeared into the tectonic zones as it appears in the highly conducting dikes which can influence the stress accumulation of tectonic earthquakes and can provide higher attenuation of the seismic waves.
\end{abstract}

\section{Introduction}

Since the first indications of the Transdanubian Conductivity Anomaly (TCA) (Ádám and Verö, 1964; Takács, 1968), a series of papers have analysed the special features and physics of the shallow (a few km deep) crustal conductor (The latest summarizing papers are: Ádám, 1992; Nagy 1996). Ádám's papers are mostly based on GGRI's magnetotelluric (MT) data measured mainly in 1970's by analog technique in the period range between 10 and $3600 \mathrm{~s}$. After selecting and digitizing the appropriate time series, the data processing has been made by Verö's program (1972). Using these results, the fundamental parameters of the TCA have already been determined (see later).

In the frame of a new EUROPROBE project supported by the Hungarian National Science Foundation (T 029443), a cooperation between the GGRI and Eötvös Geophysical Institute (ELGI) enabled the joint interpretation of about 300 magnetotelluric soundings (MTS). ELGI's 200 ones have been measured along basic lines in period range between 0.05 and $1000 \mathrm{~s}$ with a site separation of only a few km. For the modelling and inversion of this large data set (Fig. 1), mainly the program system of the "Geotools Corporation (Austin, Texas, USA)" has been used. The results of this study will be presented with special emphasis on their tectonic/seismotectonic consequences.

Copy right (c) The Society of Geomagnetism and Earth, Planetary and Space Sciences (SGEPSS); The Seismological Society of Japan; The Volcanological Society of Japan; The Geodetic Society of Japan; The Japanese Society for Planetary Sciences.

\section{The Characteristics of the MTS Curves in the TCA Area}

For demostration of the TCA's characteristics, the MTS curves measured in the Mór graben in the shallowest part of the TCA are presented in Fig. 2 (Ádám and Varga, 1990). These MTS curves show the following features:

- The apparent resistivity - in case of $\varrho_{\min }$ curves - can decrease to $0.1 \Omega \mathrm{m}$.

- The ratio of the apparent resistivities $\varrho_{\max } / \varrho_{\min }$ obtained by the rotation of the coordinate system can be as high as 1000 .

- The TCA's conductance can reach 10000 Siemens or more.

- According to the rose diagram of the $Z_{Q_{\max }}$ directions (Fig. 3), their most frequent one is NNW-SSE in the TCA's area, i.e. perpendicular to the longitudinal fractures/strike slips of the Transdanubian Central Range and of its foreground. Due to the transversal fractures of the area shown on the tectonic map (Fig. 4) and to the sedimentary basin inside and around the TCA (e.g. south of the Lake Balaton outside the TCA, and in the Little Hungarian Plain near the Rába river) there appear NNE-SSW directed $Z_{\varrho_{\max }}$ values in minority.

3. Selection of the $\mathbf{E}$ and B Polarized MTS Curves on the Basis of Their Electromagnetic (EM) Distortion and Determination of the Regional Strike Direction

Recently the decomposition technique (e.g. Groom and Bailey, 1989) is proposed to correct the impedance tensor of 


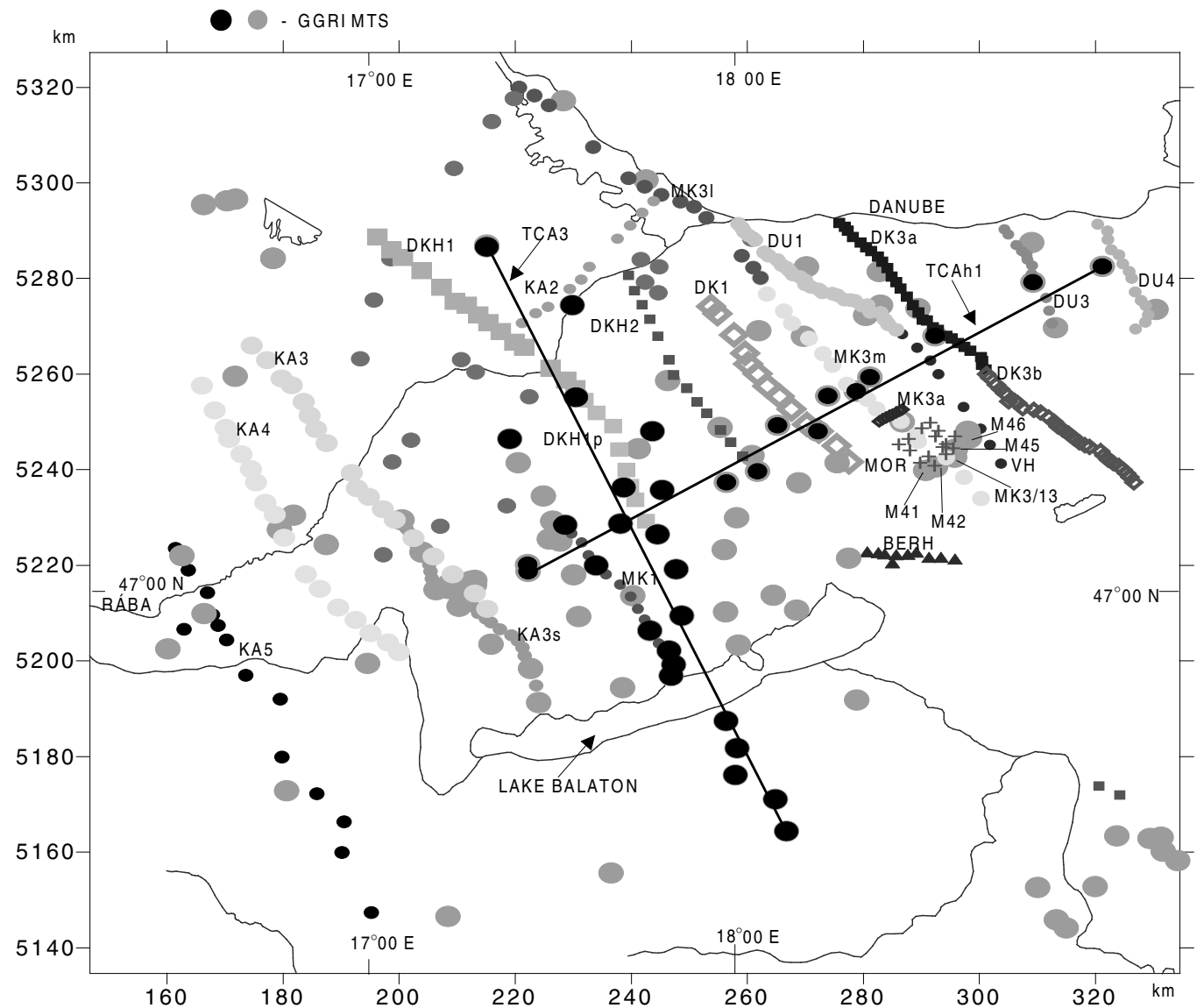

Fig. 1. MT measuring sites in the area of the Transdanubian conductivity anomaly (TCA) with profiles TCAh1 and TCA3.
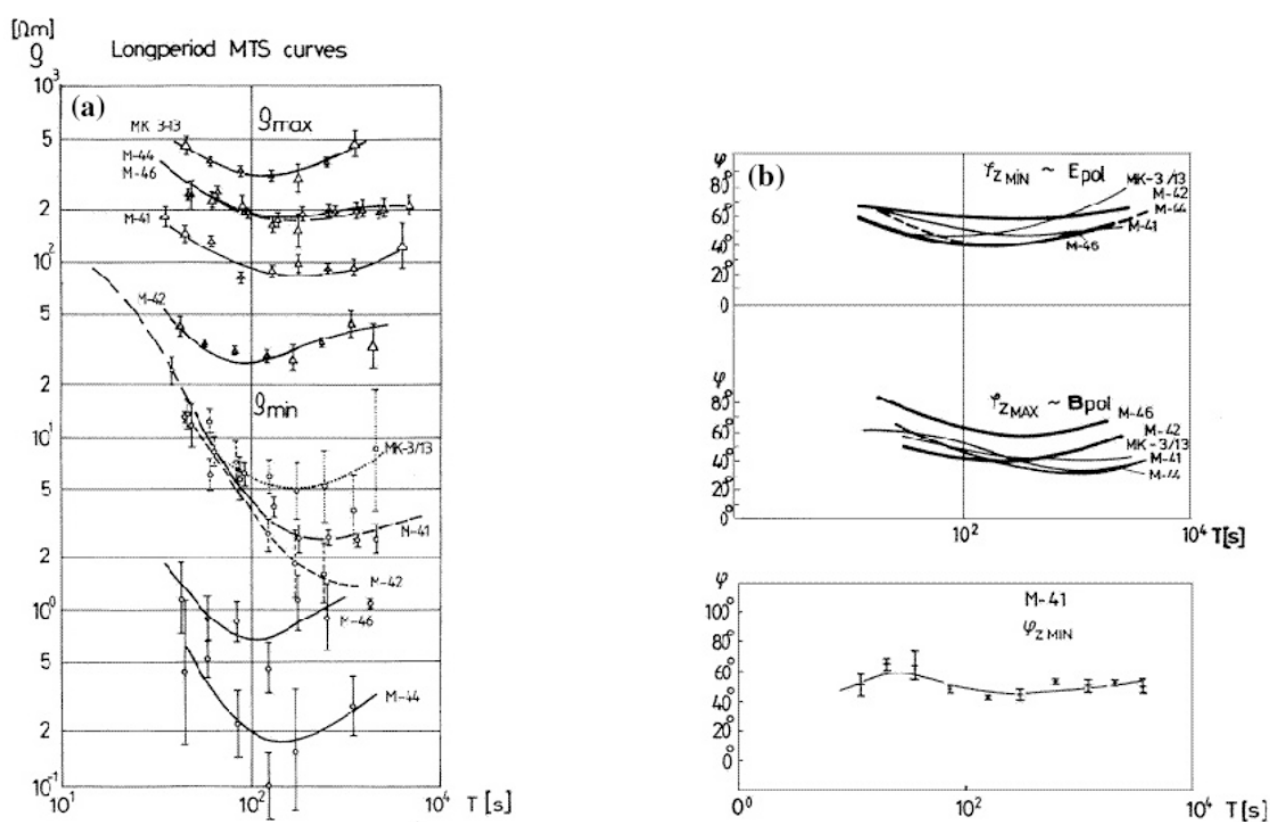

Fig. 2. Long period (deep) MT curves measured in the TCA (around town Mór) area with standard deviations (Ádám and Varga, 1990). a) apparent resistivities $(\varrho)$ vs. period $(T)$, b) phase curves $(\varphi)$ vs. period $(T)$ error bars are shown separately for M-41. 


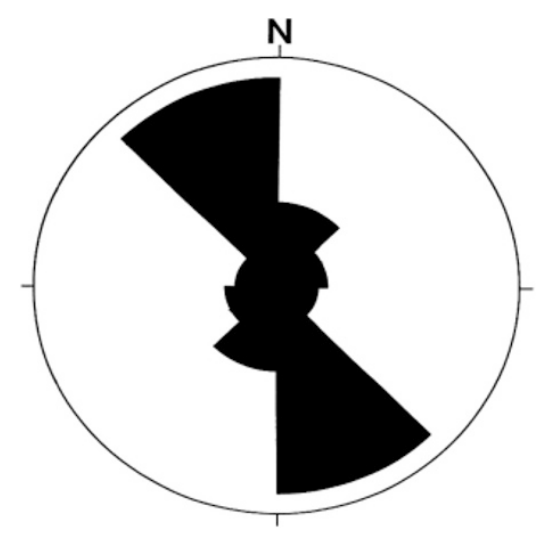

Fig. 3. Rose diagram of $\varrho_{\max }$ directions (GGRI data).

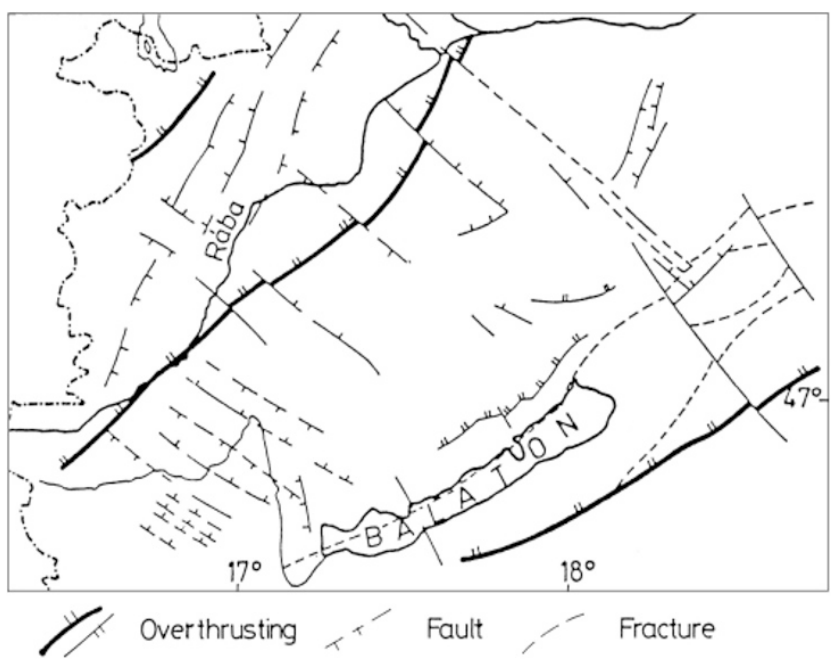

Fig. 4. Sketch on the main tectonic lines in NW Hungary (Balla, 1967).

a 2D structure from the distortion effect of a small 3D resistivity inhomogeneity. Using this technique for three ELGI profiles (MK1, MK3m, VH) the strike directions at $36 \mathrm{MT}$ sites have been summarized in a rose diagram (Fig. 5) for the period $T=10 \mathrm{~s}$, where the apparent resistivity curves best indicate the conductors (see Figs. 8(c)). The peak of the rose diagram is in about NE-SW direction.

The Groom-Bailey decomposition gave 2D strike almost perpendicular to the $Z_{\varrho_{\max }}$ direction (Fig. 3). This can explain why the extreme sounding curves $\left(\varrho_{\max }\right.$ and $\varrho_{\min }$ and their phases) have also been studied from different aspects of polarization.

As well known, the parameters of a $2 \mathrm{D}$ conductor can be best determined by E polarized MTS curves when the electric field is in the strike direction. Therefore a selection of the $\mathrm{E}$ and $\mathrm{B}$ polarized curves is needed. (In the case of B polarization, the magnetic field follows the strike direction.) For this purpose, there are different techniques in the MT practice. If the geological structure really is of $2 \mathrm{D}$ character and its strike can be followed on the surface (in outcrops of the formations), this geological method is to be chosen. Another method could be based on the character of the EM distortion of the sounding curves. Concerning the gal-

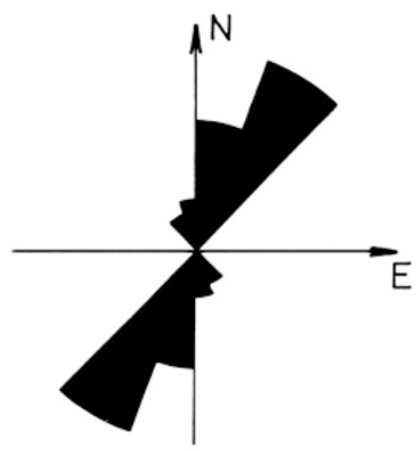

$T=10 \mathrm{~s}$

Fig. 5. Rose diagram of the Groom-Bailey strikes determined at $T=10 \mathrm{~s}$ from the data of $36 \mathrm{MT}$ sites measured along the profiles MK1, MK3m and $\mathrm{VH}$.
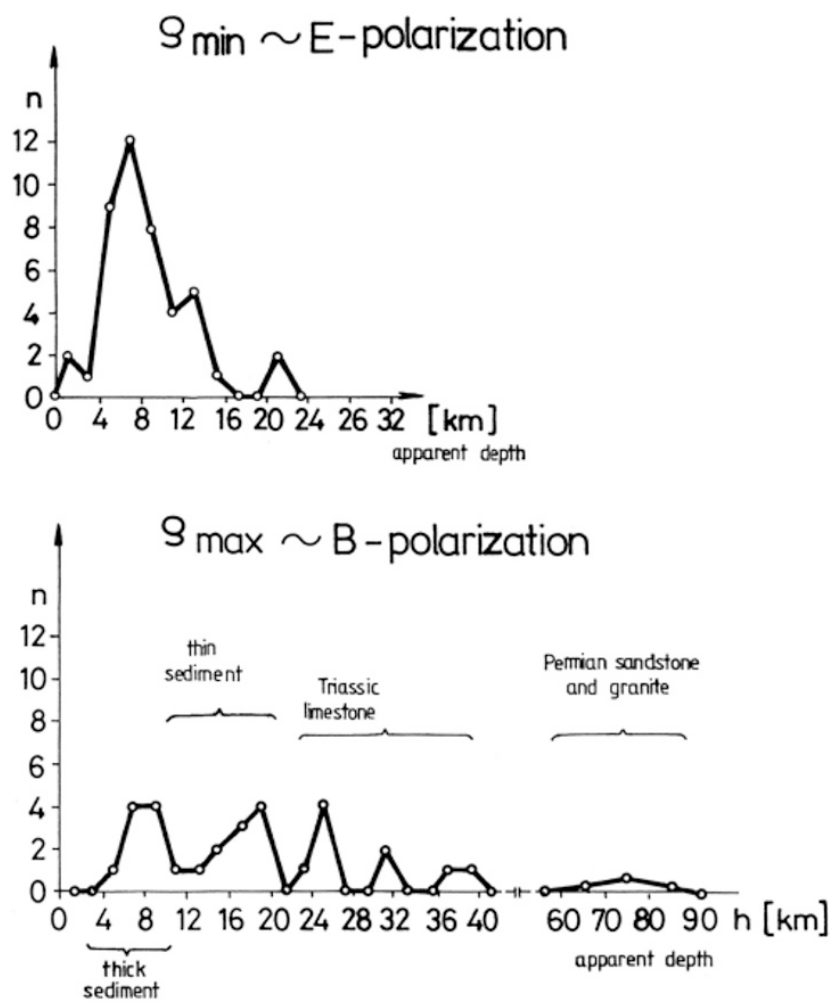

Fig. 6. Relation between the apparent depth of the crustal conductor in the TCA area calculated from the $\varrho_{\max }$ (below) and $\varrho_{\min }$ (above) curves and the near-surface geological formations (MT measurements of GGRI).

vanic distortion Berdichevsky (1999) wrote: there are "two kinds of static shift": (1) the $\varrho$-effect caused by small nearsurface inliers and (2) S-effect caused by variations in the integral conductance $(\mathrm{S})$ of the upper conductive layer .... In the ideal 2D model they act upon transverse (B polarized) $\varrho_{A}$-curves and do not touch longitudinal (E polarized) $\varrho_{A}$ curves. "Behind both effects are the same galvanic mechanisms, but they operate in different frequency intervals."

If the effect of a small near-surface body is superposed to the 2D structure, both polarizations are distorted.

The E polarized curves are distorted by side effects i.e. the induction effect of nearby conductive zones. This appears 

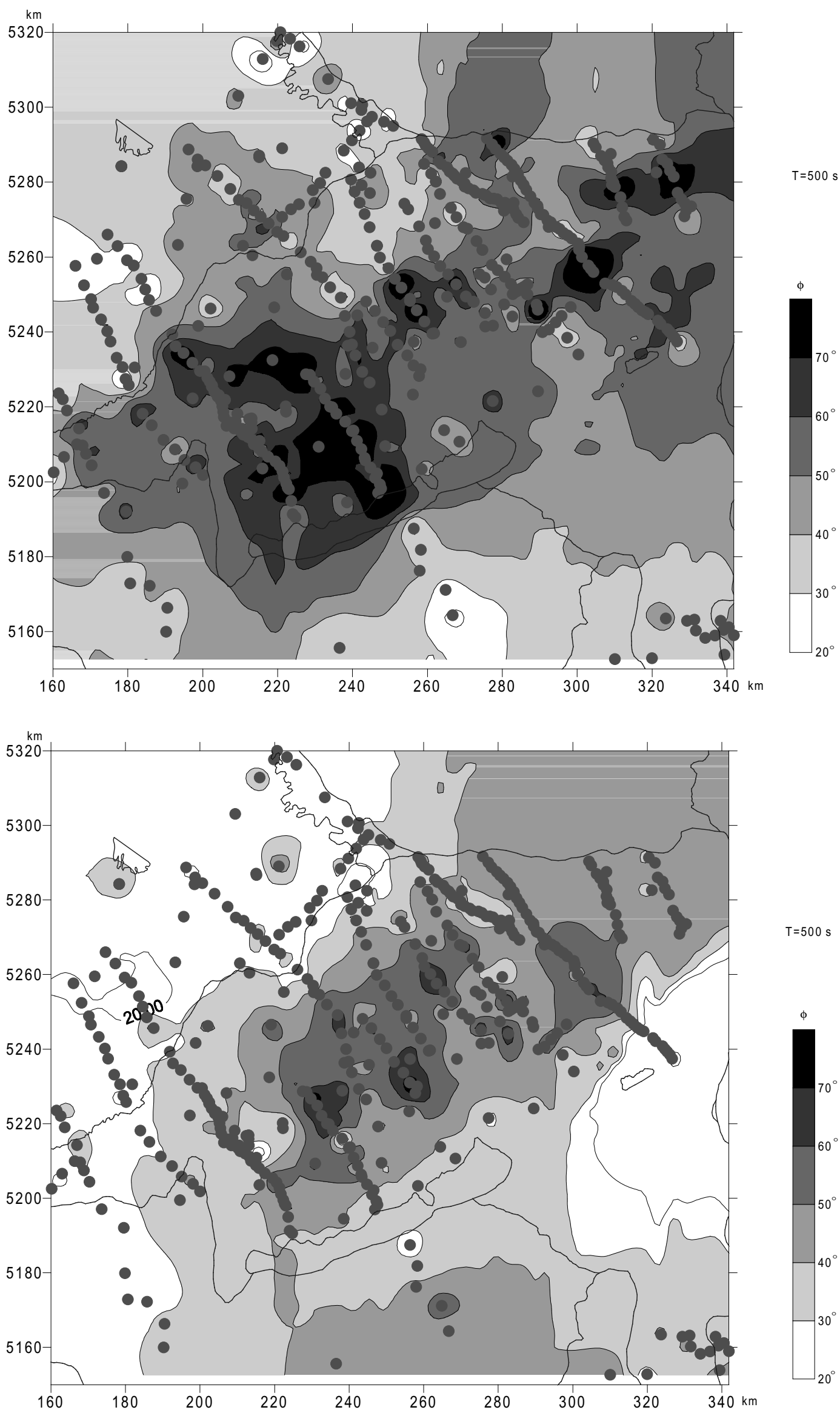

Fig. 7. Qualitative image of the conductivity structure as a $2 \mathrm{D}$ frame shown by the phase values belonging to the $\varrho_{\min }$ (a) and $\varrho_{\max }$ (b) values at period $(T)=500 \mathrm{~s}$. 

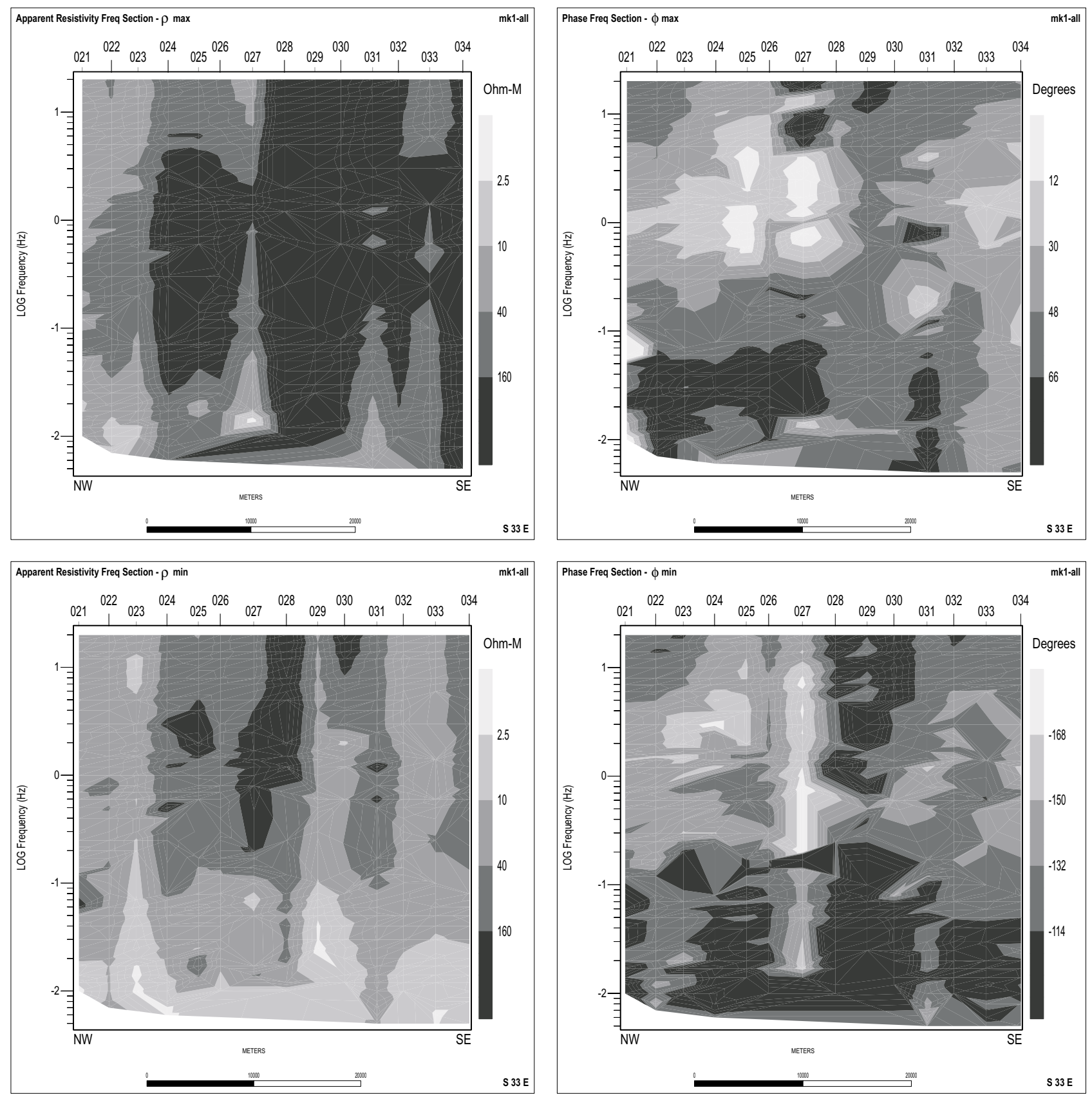

Fig. 8(a). $\varrho_{\min }$ and $\varrho_{\max }$ pseudosection and their phases along the MK1 profile.

only at short periods where it causes apparent conductivity anomalies.

Of course, in case of a 3D structure neither the polarization of the sounding curves, nor their distortion can be separated.

An interesing phenomenon appeared in case of the sounding curves measured in the TCA area. As a first approximation the extreme sounding curves $\left(\varrho_{\max }\right.$ and $\left.\varrho_{\min }\right)$ were determined (Ádám, 1981). It was observed that the decreasing branches of the $\varrho_{\min }$ curves indicating the conductor ran together, and in case of the $Q_{\max }$ curves these branches scattered along the $\varrho$ axis, i.e. the static shift is a typical S-effect and it is connected to the $\varrho_{\max }$ curves which should be taken as B polarized ones. This special character of the sound- ing curves was studied in more detail by different statistical techniques hinting at the strong 2D character of the conductivity anomaly.

The distribution of TCA's apparent depth values determined by $1 \mathrm{D}$ inversion from the GGRI's $\varrho_{\min }$ and $\varrho_{\max }$ curves has been studied in connection with the surface rocks (Ádám, 1981). Figure 6 shows this empirical relation separately in case of $\varrho_{\min }$ and $\varrho_{\max }$ curves. Only the apparent depth values from $\varrho_{\max }$ are shifted proportionally with the resistivity of the surface formations, i.e. the $\varrho_{\max }$ curves are of B polarization as stated by Ádám (1981) and Ádám and Varga (1990). The same conclusions could be drawn from the relation between apparent depth values vs. conductance of the surface sediment of low resistivity. Especially 


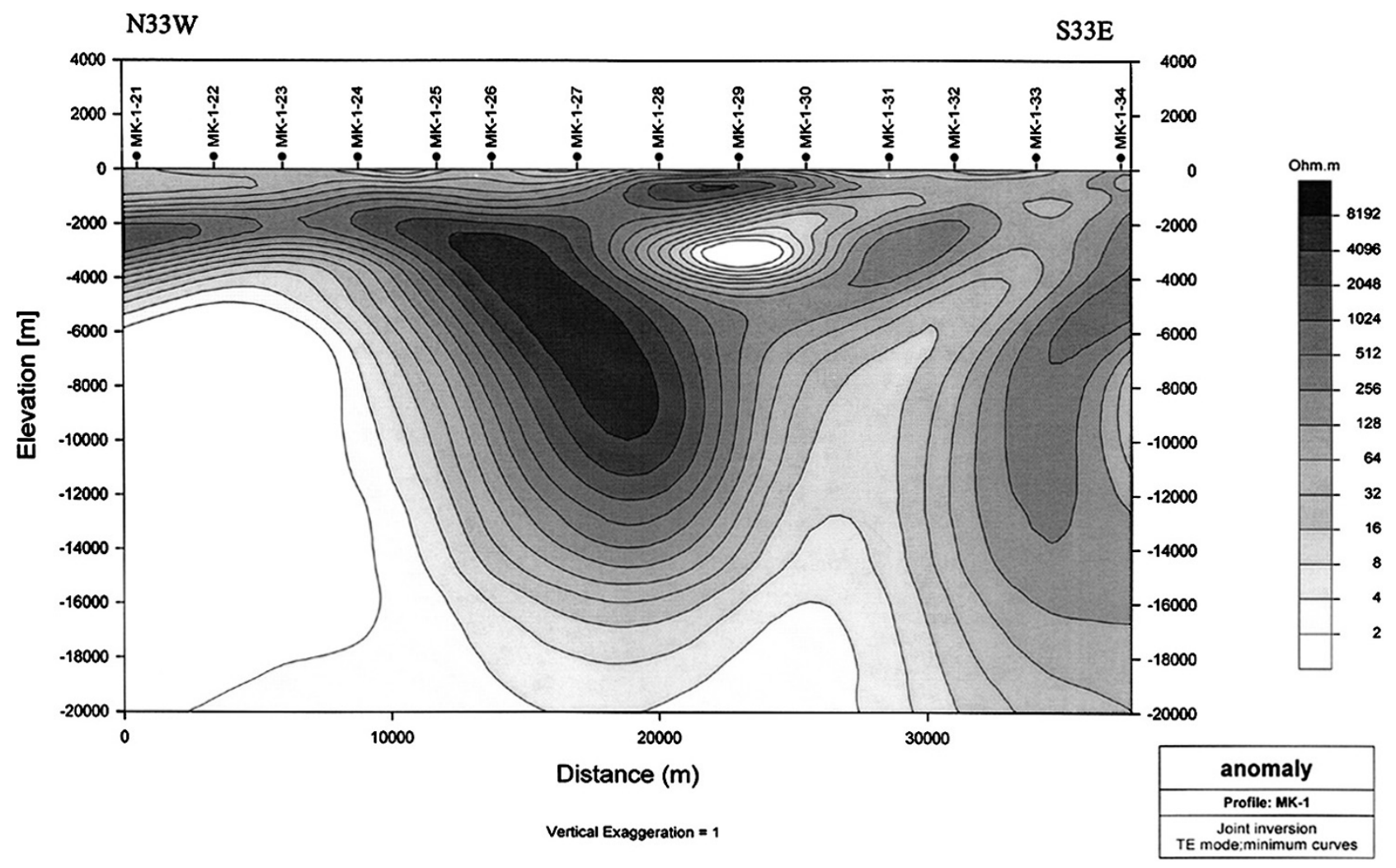

Fig. 8(b). 2D mixed inversion model of MK1 profile when $\varrho_{\text {min }}$ curves lying in the regional strike direction (NE-SW) are taken E polarized ones computed by Rodi and Mackie (2001) 2D inversion code.

the relation between the conductance of the TCA vs. its apparent depth clearly shows the determining role of the $\varrho_{\min }$ curves as E polarized ones in the study of the structure of the TCA (Ádám, 1981). Therefore, such structural models are to be found for the TCA at which the $\varrho_{\max }$ curves represent the B polarization. The $\varrho_{\min }$ curves as E polarized ones give the most probable parameters for the TCA. On the other side, as the E polarized $\varrho_{\text {min }}$ curves could be distorted at their short period part, the B polarized $\varrho_{\max }$ curves have to be used for mapping the surface structures (sedimentary basins) after Berdichevsky et al. (1998).

According to the rose diagram of the $Z_{\varrho_{\max }}$ directions (Fig. 3) the average direction of the $\varrho_{\min }$ curves indicating the conductor is about NE-SW.

Phase mapping is a good tool for a qualitative image of the conductivity structure and first of all for the determination of the regional strike direction. In Fig. 7 the phase maps belonging to the extreme $\varrho$ curves can be seen which represents a quasi $2 \mathrm{D}$ conductivity structure elongated in NESW direction. Inside this frame there is another quadrangle structure with higher phase values (greater than $60^{\circ}$ ) which is bordered by the longitudinal (NE-SW) and transversal (NW-SE) tectonic lines. This rough map also emphasizes the determining role of these two main tectonic line systems. Among them the NE-SW strike is more important in agreement with the rose diagram (Figs. 3 and 6).

\section{TCA's Models}

The study on the EM distortions laid the foundation of the choice of the appropriate geoelectric model. It is very probable that a conducting dike (Ádám, 1987) or a dike system (Ádám, 1981, 1996) may fulfil the preconditions determined by the polarization of the $\varrho_{\max }$ and $\varrho_{\min }$ curves. This can be proved by many densely measured MT profiles, e.g. by the pseudosections (Fig. 8(a)) and 2D model (Fig. 8(b)) of ELGI's profile MK1 inverted by the GEOSYSTEM WinGlink 2D inversion program (Rodi and Mackie, 2001) using both B $\left(\varrho_{\max }\right)$ and E $\left(\varrho_{\min }\right)$ polarization where the $\varrho_{\min }$ direction corresponds to the regional strike. Figures $8(\mathrm{a})$ and 8 (b) show conducting narrow dikes emerging from a conducting layer. These dikes rise near the surface around MT sites 23 and 29 supposedly in fracture/strike slip zones. They border resistive blocks. The dikes appear on the phase pseudosections, too, with values much greater than $45^{\circ} / 135^{\circ}$ (Fig. $8(\mathrm{a})$ ). The resistivity in the dike is less than $1 \Omega \mathrm{m}$. There is a great difference between the resistivity of the dike in case of $\varrho_{\max }$ and $\varrho_{\min }$ pseudosections. The conducting dike appears first of all on the $\varrho_{\min }$ sections. The $\varrho_{\max }$ apparent resistivity could be much greater than $\varrho_{\min }$ in the dike. This anisotropy is also an important aspect for the model choice. Starting from the above mentioned statements the following numerical models have been chosen: Figure 9 shows our traditional, often referred (one) dike model (first computed by Tátrallyay, 1977). In Fig. 10, a dike system can be seen consisting of narrow, parallel dikes isolated from each other (Ádám, 1981, 1996). In both cases a conducting basement has been inserted at a depth of $70 \mathrm{~km}$ corresponding to the asthenosphere in the Pannonian basin. Of course, if the depth of this conductive halfspace is decreased, or the halfspace is substituted by a conducting layer 

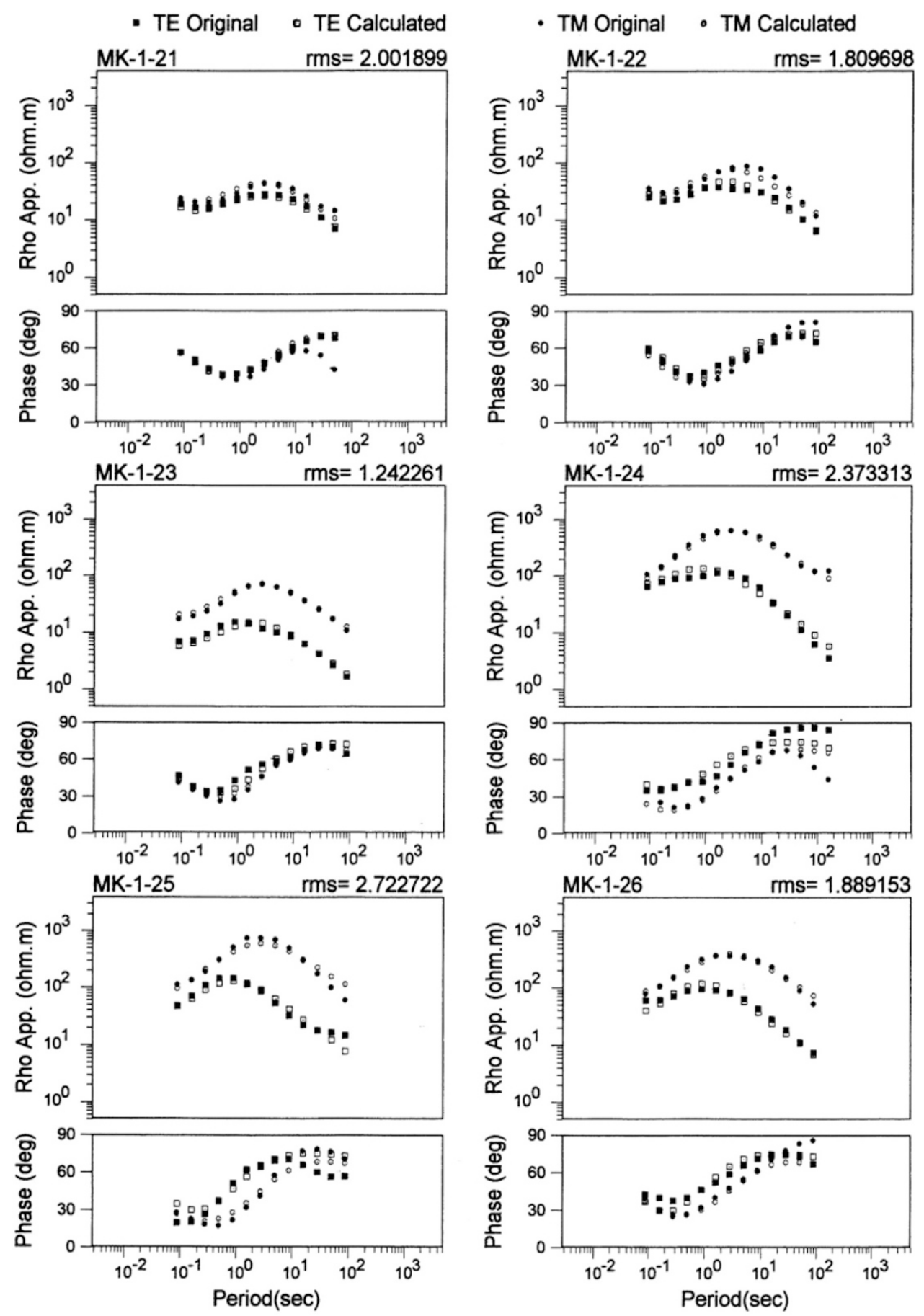

Fig. 8(c). Fitting between the measured and calculated (model) curves.

we can get the real structure of the TCA shown by Figs. 8(a) and 8 (b) consisting of the conducting dikes and of a conductive layer below these dikes. These models fulfil the preconditions derived from the pseudosections. Especially great is the difference between the two polarizations in Fig. 10, where the B polarized curves do not indicate the dike system. Eisel and Haak (1999) came most recently to the same conclusion interpreting the magnetotelluric sounding curves measured around the German deep borehole (KTB) by parallel dike system corresponding to the fractures of the area containing graphite (ELEKTB Group, 1997). According to their figure 11 the $\varrho_{\min }$ curves are of E polarization in case of 1D anisotropic, 2D intrinsic and 2D macroscopic (due to dike system) anisotropic structure.

\section{The Main Characteristics of the TCA Based on Induction Vectors}

The main regional features of the TCA can be delineated by the Wiese induction vectors (arrows). As is shown in Fig. 11 (Wallner, 1977), there are two conducting zones of about $15-20 \mathrm{~km}$ widths elongated in the direction of the longitudinal fractures (NE-SW) given by the minimum values of the Wiese vectors at $T>20 \mathrm{~min}$. Outside these zones the vectors point north- or southwards i.e. towards 

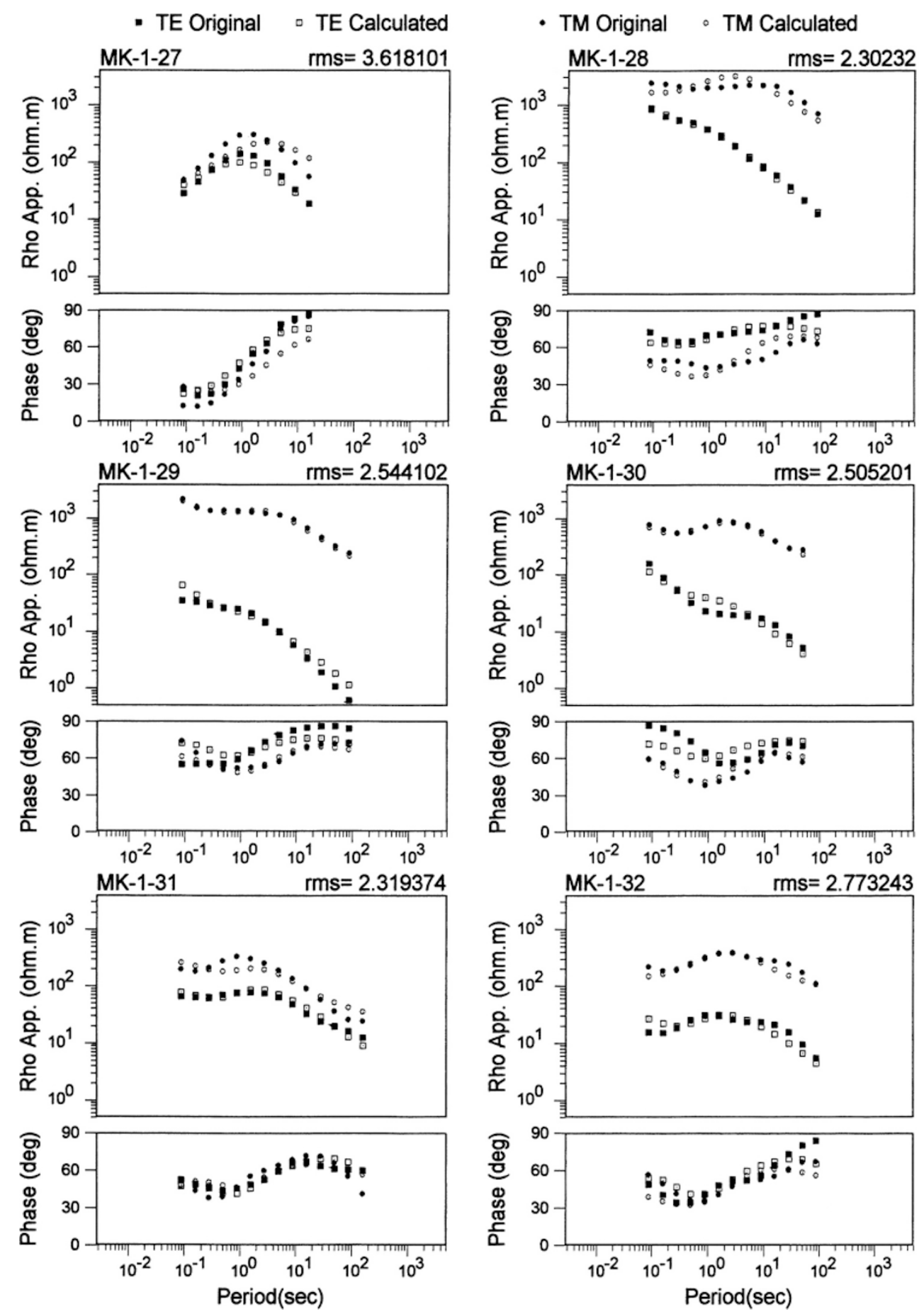

Fig. 8(c). (continued).

the more resistive geological formations. Inside the conductors the length of the vectors is generally less than 0.1 (i.e. the ratio of the vertical $(Z)$ to horizontal $(H)$ geomagnetic components at a given period). These vectors are directed mainly parallel with the longitudinal fractures (Fig. 4), i.e. with the regional strike of the anomalous zones. This peculiarity clearly appears in the famous 2D Carpathian CA, too (Jankowski et al., 1984). It can also be explained by 3D effects inside the conductive zones (Arora and Ádám, 1992) as it has been proved by Wannamaker et al.'s (1984) 3D numerical model. In their Fig. 14 the tipper strikes rotate inside the elongated 3D conductor and in its center they are perpendicular to the longer axis of the conductor. If $3 \mathrm{D}$ dike structures also appear at the crossing (junction) of the longitudinal and transversal tectonic lines (zones) in the TCA area these dense 3D conducting dikes fall into a line (zone) e.g. along the NE-SW TCA $h_{1}$ profile (Fig. 1) determined by the SW directed induction arrows. Hence they form a quasi 2D structure. The $\varrho_{\min }$ curves without static shift (S-effect!) distortion are mainly in the strike of this quasi 2D structure therefore they are of E polarization.

Between the two conductive zones the vectors turn south- 

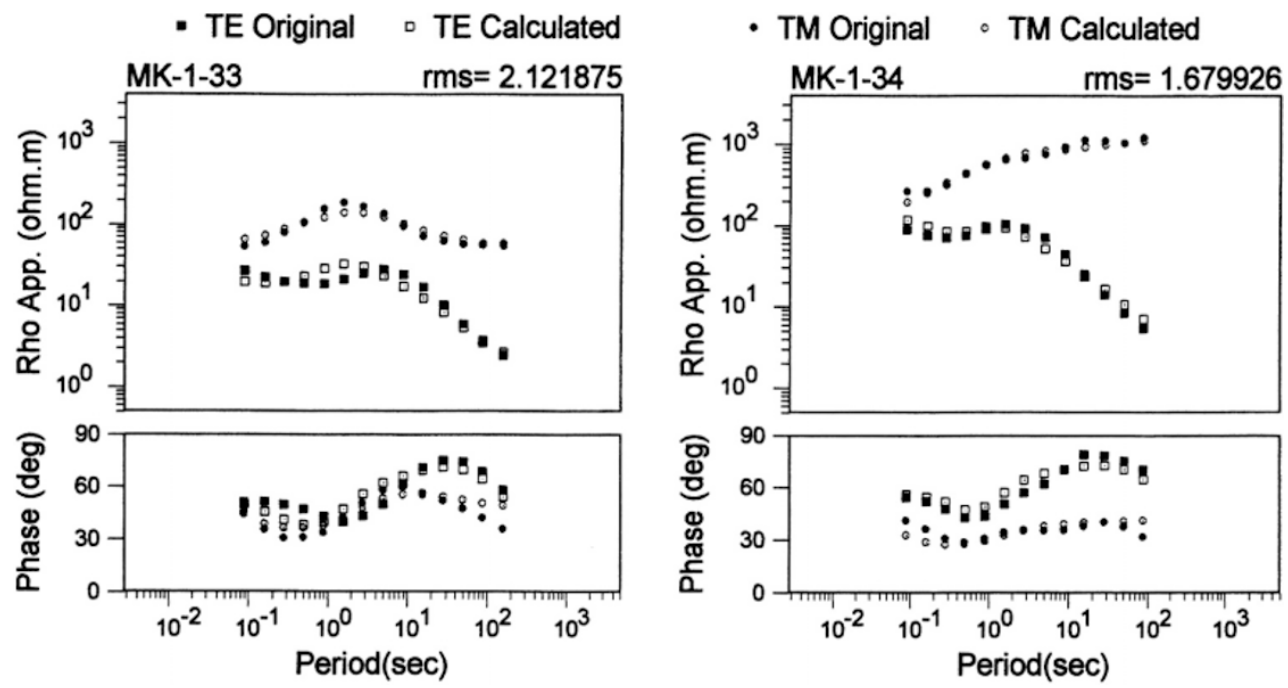

Fig. 8(c). (continued).

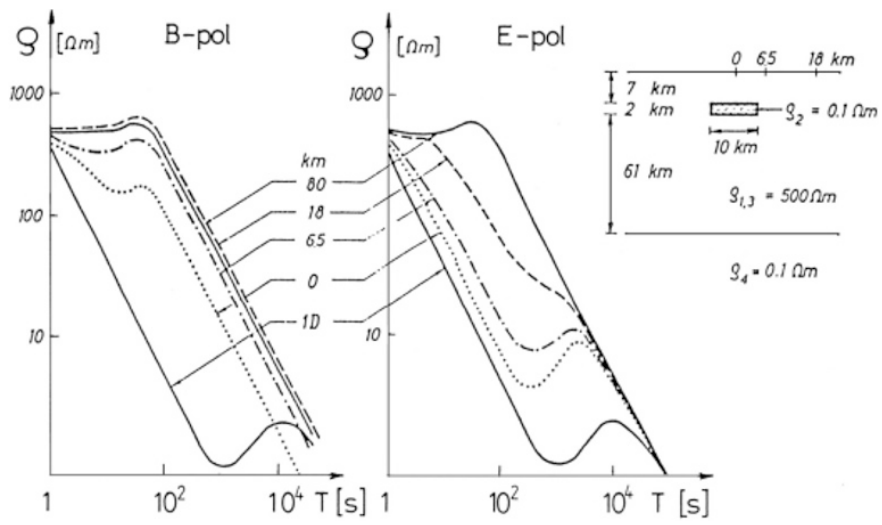

Fig. 9. 2D model curves of a conducting dike in dependence of the distance of the dike centre (after Tátrallyay, 1977).
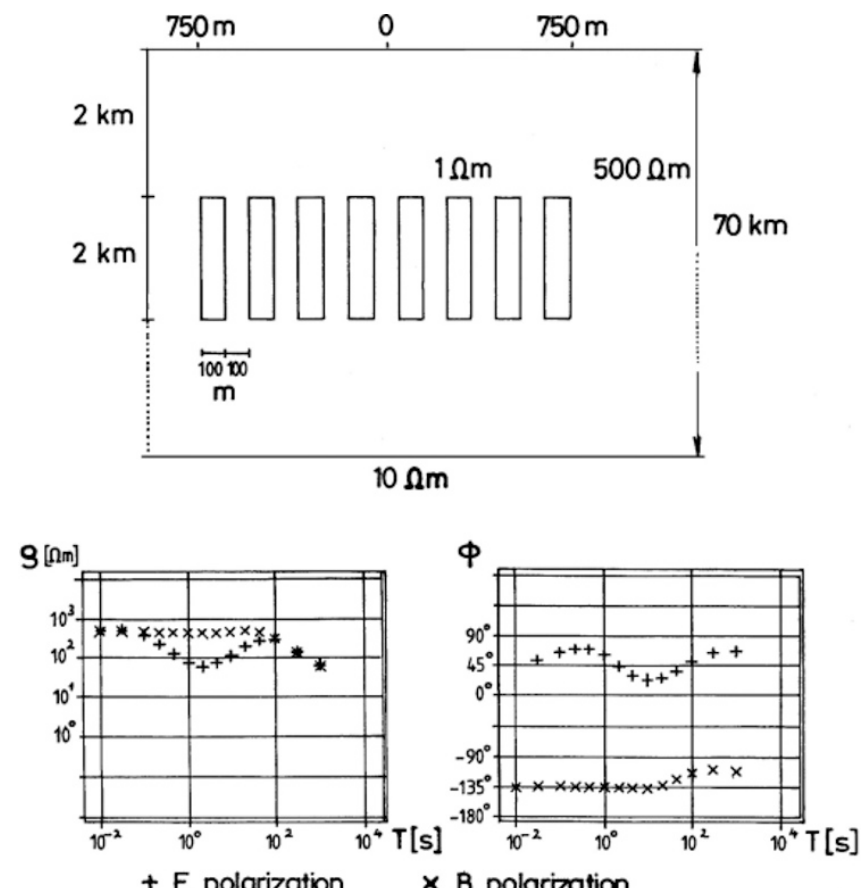

Fig. 10. E and B polarized sounding curves due to conducting dike system embedded in resistive matrix with conductive asthenosphere (Ádám, 1996). 


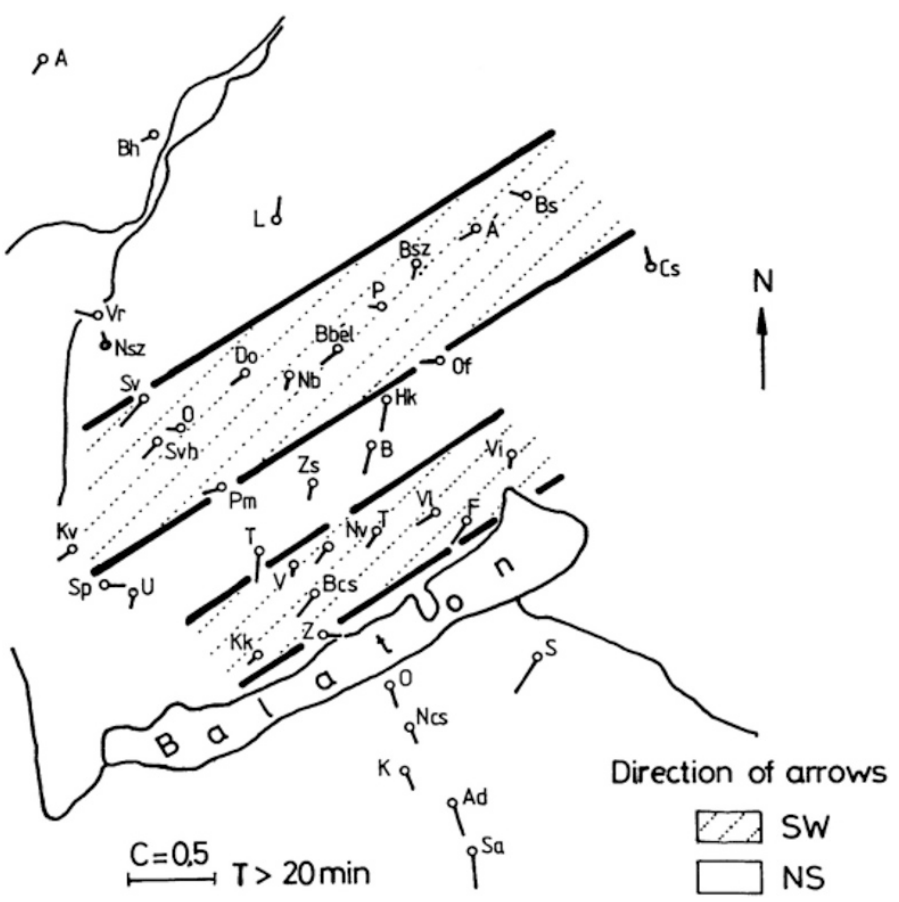

Fig. 11. Long period Wiese-arrows in the area of the TCA (Wallner, 1977).

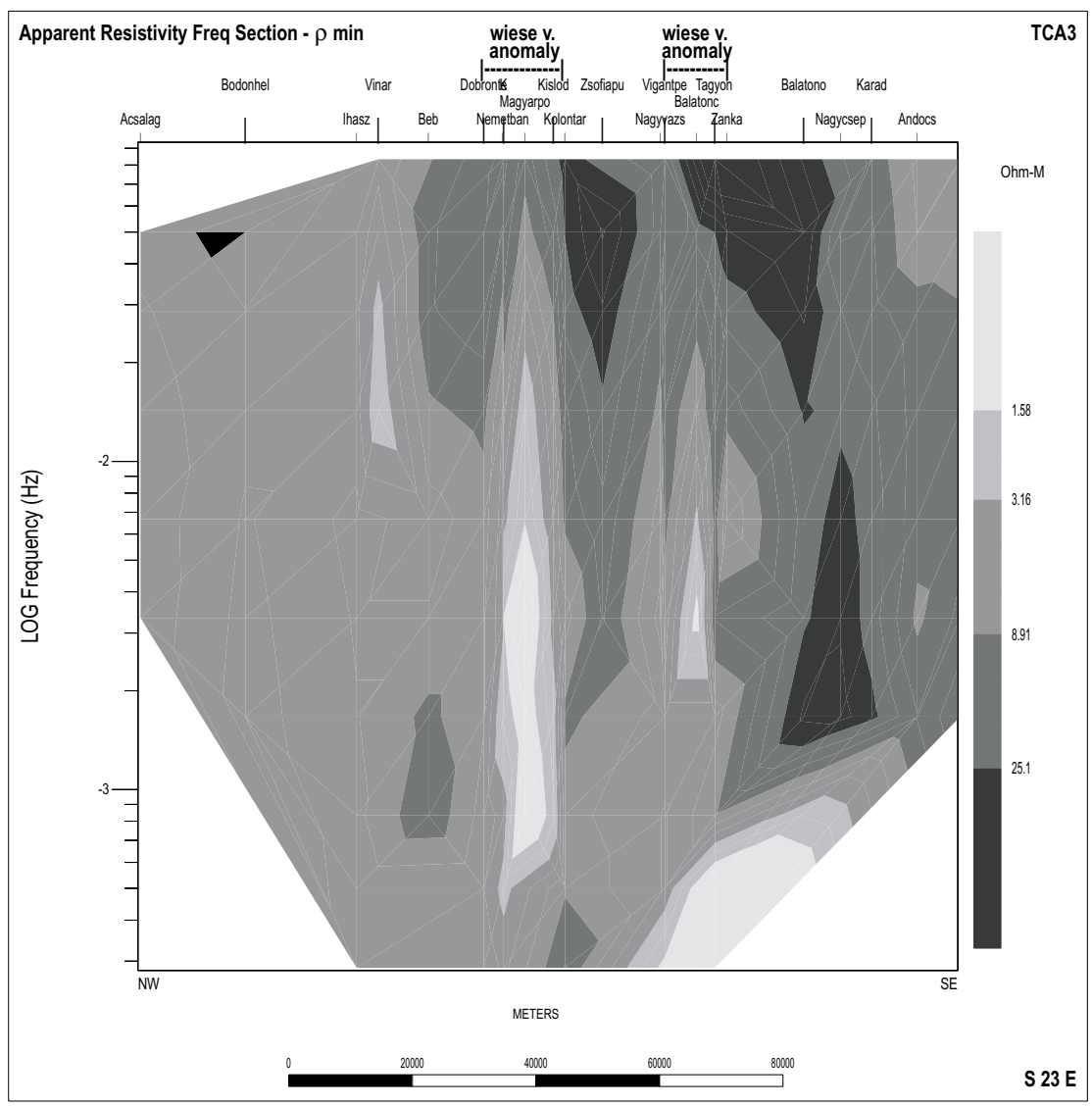

Fig. 12. $\varrho_{\min }$ pseudosection perpendicular to the conductive zones (TCA3) indicated by Wiese-vectors in Fig. 11. 

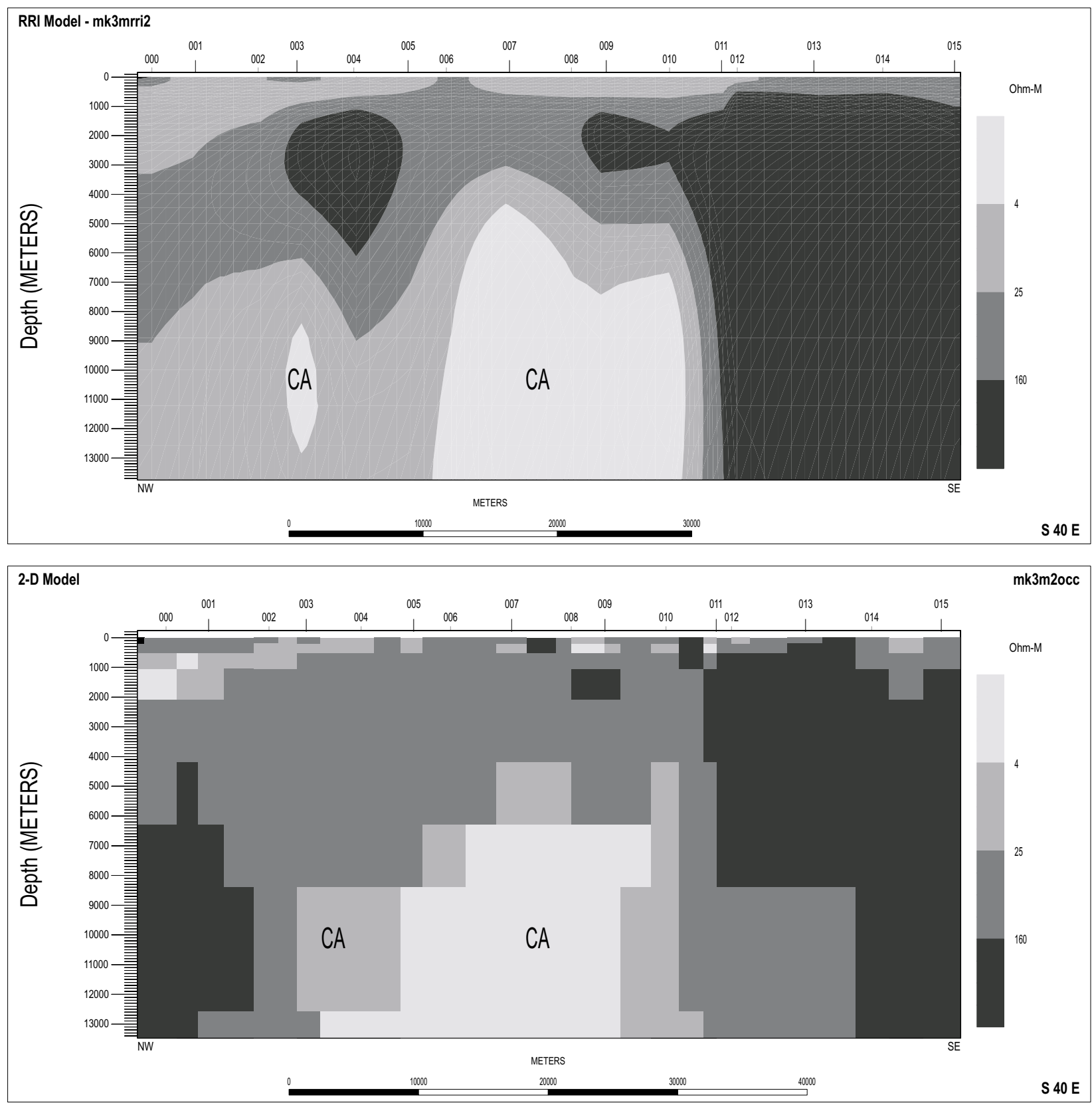

Fig. 13. a) The 2D RRI inversion, b) Occam inversion of the MK3m profile. Both TE and TM modes have been used.

ward showing that this southern zone is less conductive.

The conducting stripes indicated by long period Wiese vectors can be compared with conductivity anomalies appearing on the $\varrho$ pseudosection along the TCA3 crossing them in NW-SE direction (see the location in Fig. 1). The horizontal position and dimension of the conductors in the $\varrho$ pseudosection correspond to the anomaly stripes detected by the induction vectors (see in Fig. 12 the "Wiese vector anomaly") in close connection with the conductors appearing in Fig. 8(b).

\section{General Structure of the TCA as Shown by Pro- files}

As mentioned, there are differences in the period range measured by GGRI and ELGI. GGRI measured the geomag- netic variations by static variometers and ELGI by induction coils. GGRI could detect the bottom of the conductor with long enough period variations, too. The distance between MT sites was at the same time shorter in case of ELGI's measurements, hence its spatial resolution was better, than that of the GGRI.

The 2D inversion has been made along selected ELGI profiles which are mostly directed in about NW-SE. All sounding curves were computed in the direction of the regional strike (NE-SW) with rotation of the coordinate system and this direction has been taken as E polarized one which is in many cases near to the $\varrho_{\text {min }}$ direction. Generally RRI inversion (Smith and Booker, 1991) has been used except in case of MK1 profile where the Win Glink code (Rodi and Mackie, 2001) has been applied for a comparison with 

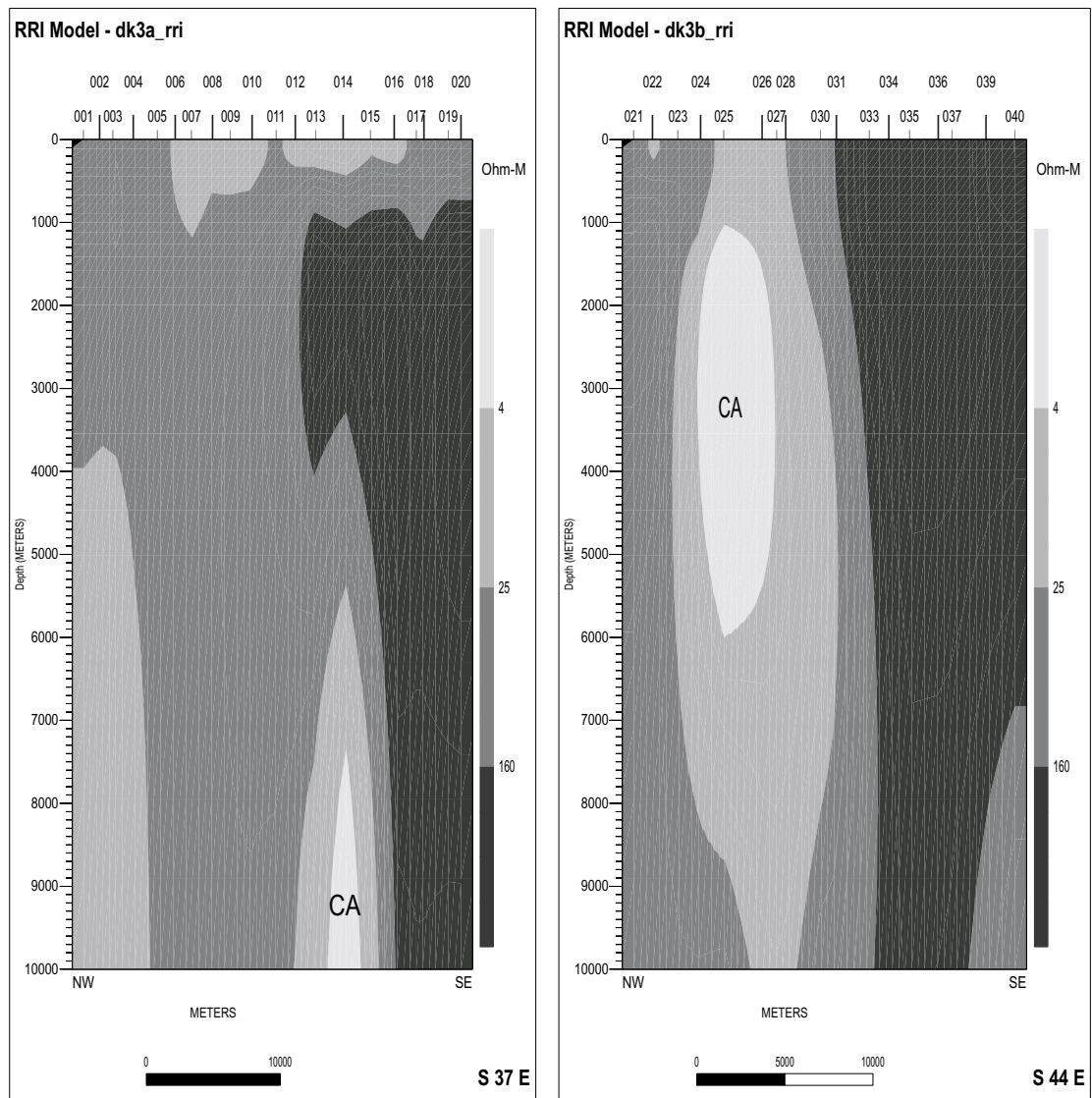

Fig. 14. The 2D RRI inversion of the DK3 profile in two segments (DK3a and DK3b) in the NE part of the TCA. Both TE and TM modes have been used.

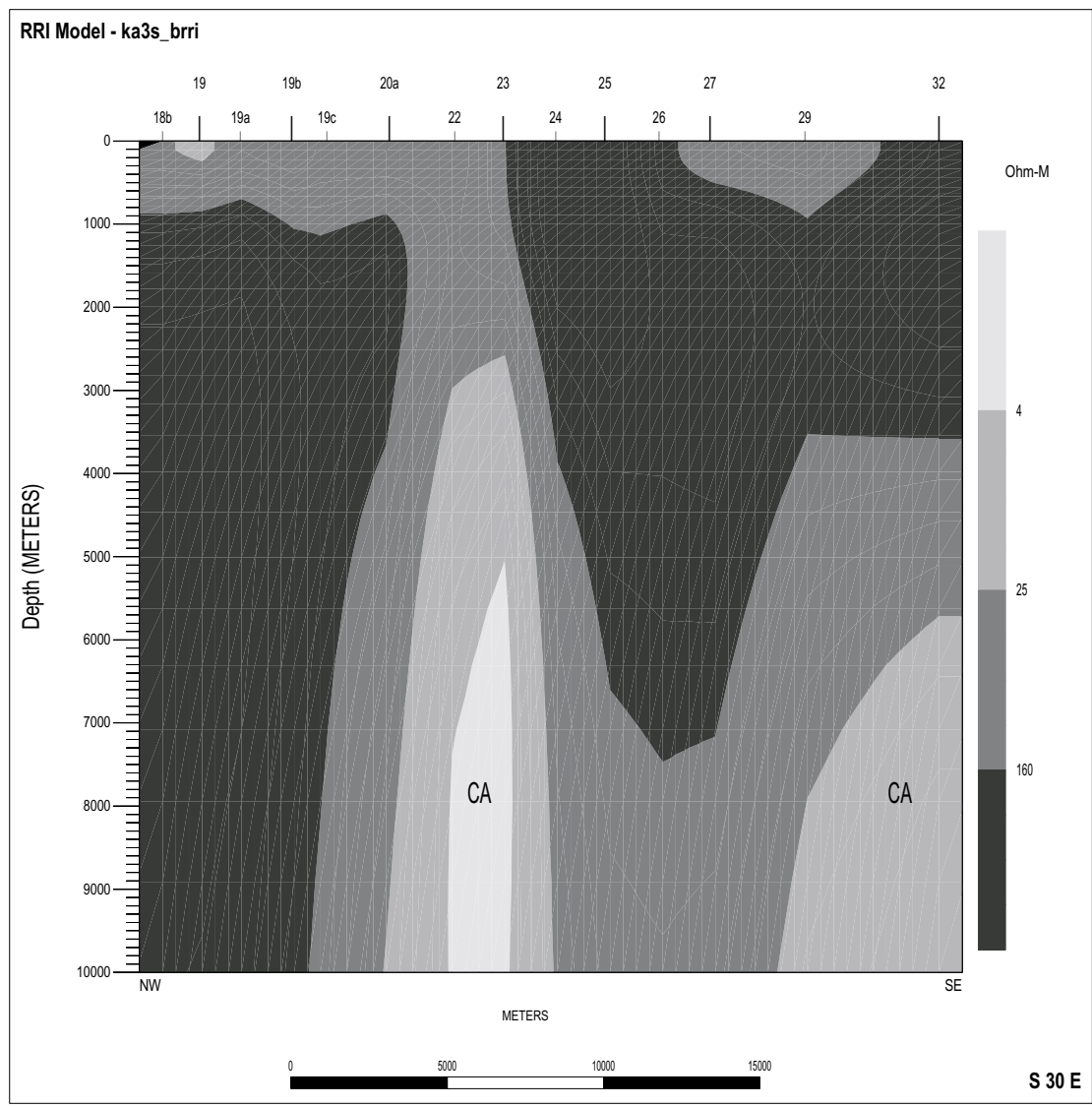

Fig. 15. A segment of the RRI inversion of the KA3s profile (in SW part of the TCA). Both TE and TM modes have been used. 


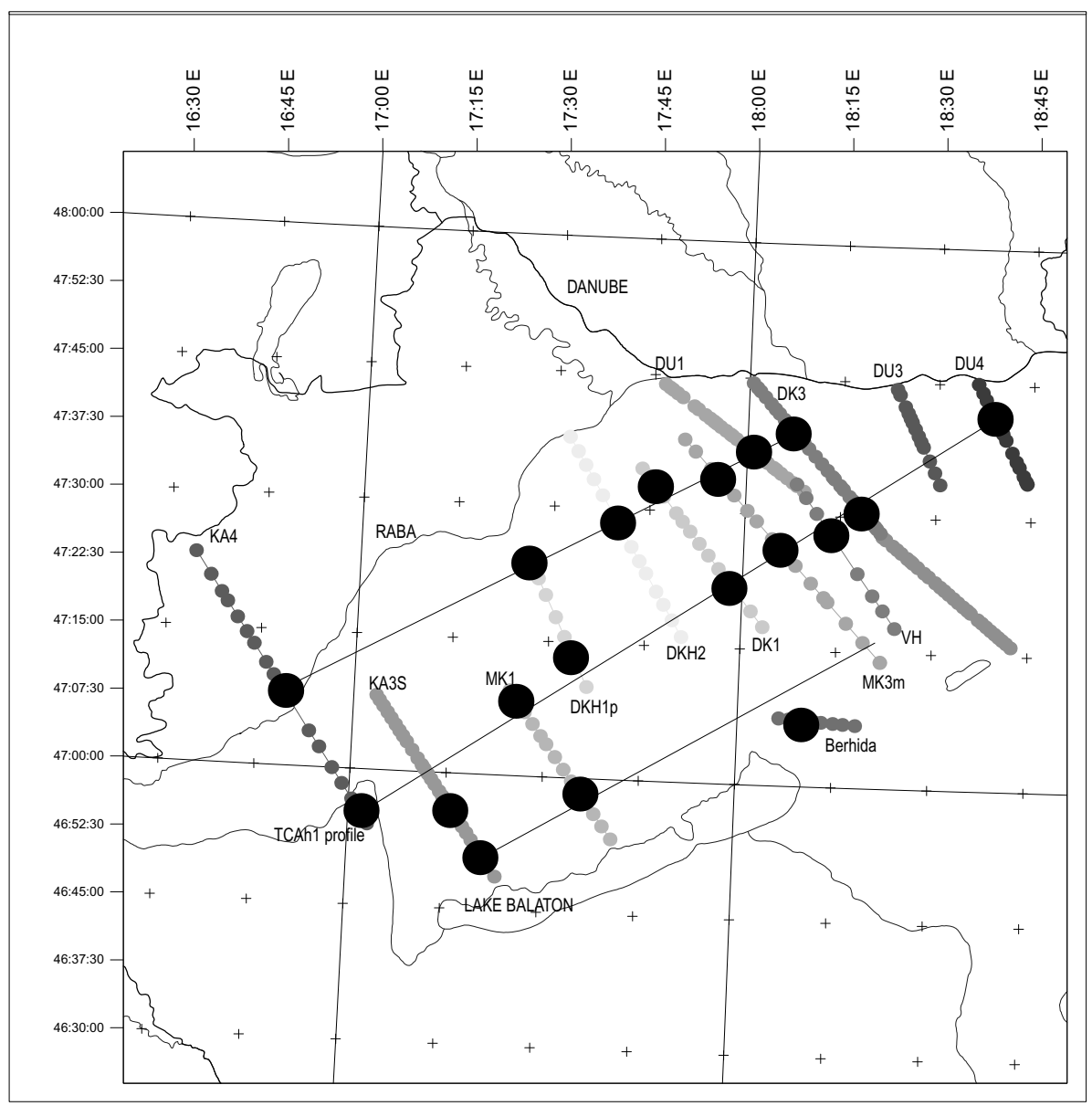

Fig. 16. A map on the conducting dikes with great dots on the ELGI profiles.

RRI (Fig. 8(b)). In some cases both the RRI and the Occam inversion (Constable et al., 1987) have been computed e.g. for MK3m profile as can be seen in Figs. 13(a) and 13(b). Here the CA beneath sites $7-10$ is near to the Mór graben being seismically active region which was studied in detail by magnetotellurics (Ádám and Varga, 1990) and conductor was found in the whole graben in elevated position (at a depth of about $3 \mathrm{~km}$ ). Further selected examples of the RRI inversion are shown in Figs. 14(a) and 14(b) for the profile DK3a and DK3b. At the site 014 the most northern longitudinal fracture appears where the highly resistive Mesozoic rocks are pinching out in contact with the sediments of the Little Hungarian Plain (Fig. 14(a)). At the site 025 in Fig. 14(b) the most active tectonic zone is indicated corresponding to the TCAh1 profile (Fig. 1) and to the northern zone in the SW directed Wiese arrows in Fig. 11 (see the $\mathrm{CA}$ in this zone in Fig. 13, too). The southern conductive zone also along a longitudinal fracture - north of the Lake Balaton - appears in the MK1 profile (Fig. 8) and at the site 29-32 of the profile KA3s in Fig. 15.

The conducting bodies (dikes) often strech into unprobably great depth. The thickness of the dikes is supposedly smaller and therefore their resistivity may be less than $1 \Omega \mathrm{m}$ due to the S-equivalence.

The conductivity anomalies less than about $10 \Omega \mathrm{m}$ de- termined by 2D inversion of NE-SW directed MT sounding curves are summarized in Fig. 16 by the great dots on the profiles. These can be connected by three NE-SW directed lines, i.e. the MT profiles are crossed by three great longitudinal fractures or strike slip zones. The most northern one corresponds to the border or pinching out of the Mesozoic limestones, as mentioned and shown by a detailed geological map based mainly on boreholes (Fig. 17). The two other ones correspond to the anomalous zones of the induction vectors (Fig. 11). South of the Lake Balaton, Varga (1979) detected a narrow conducting zone parallel to those described above. This is shown by the tectonic map in Fig. 4 by a short thick line, so-called Balaton line.

The average depth of the conducting dikes is about $4 \mathrm{~km}$. In some cases they come nearer to the surface. Their conductance is generally greater than 5000 Siemens and in some cases reaches more than 10000 Siemens according to $1 \mathrm{D}$ inversion.

Studying the whole magnetotelluric data one can suppose that the conducting dikes (fractures) emerge from the Paleozoic Upper Austroalpine units which form a deep syncline below the Mesozoic units reaching with its axis to a depth of about $10 \mathrm{~km}$ (only geological supposition!). It is hard to estimate the real depth of the conducting layer due to the induction (side) effect of the conducting dikes. 


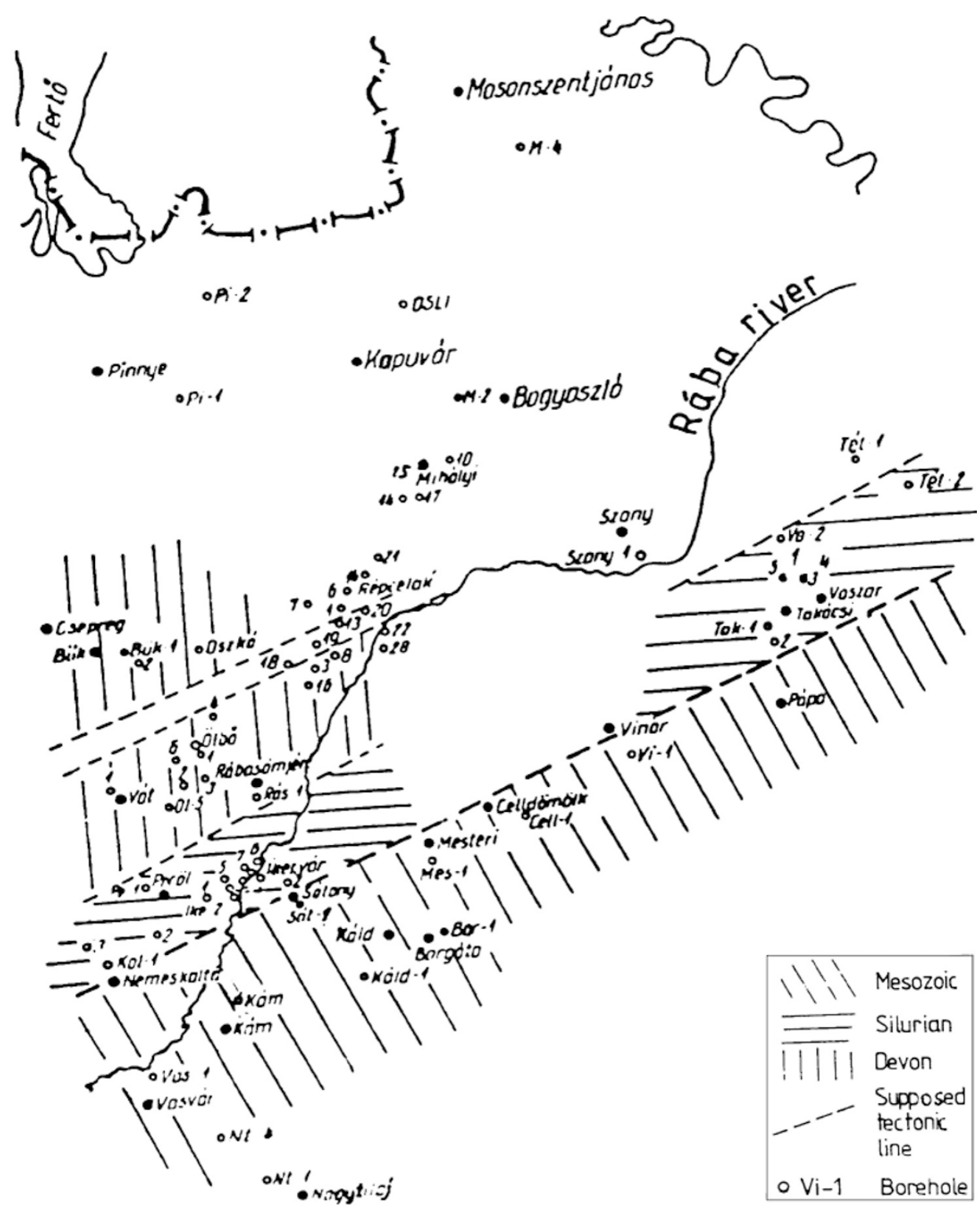

Fig. 17. The contact zone of the Mesozoic and Paleozoic rocks along a tectonic line determined by boreholes (Balázs, 1967).

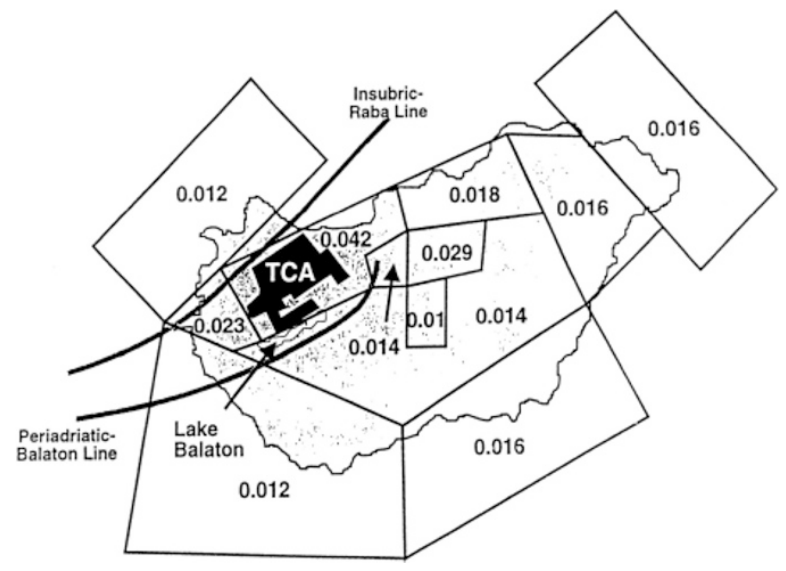

Fig. 18. Attenuation coefficients in the area of the Carpatho-Pannonian region after Zsíros (1985).

\section{Material of the TCA}

The material of the conductor may be graphite, or graphitic film (black shale) and fluid. This supposition is supported by the peculiarities of the magnetotelluric sounding curves described in Section 2, as follows:

- resistivity could be as low as $0.1 \Omega \mathrm{m}$

- great conductance

- high anisotropy $\left(\varrho_{\max } / \varrho_{\min }\right.$ ratio $)$.

Great conductance (thousands S) could only be due to electronic conduction (e.g. Zhamaletdinov, 1996). As there is not any borehole sample and the TCA does not outcrop, only the summarized features (parameters) can help us to find the material of the conductor. As seen in Figs. 8, 1315 the conducting material often accumulates in the tectonically weak zones (shear zones) forming conducting dikes. This phenomenon may hint at shear precipitation of the carbon. The connectivity of carbon is increased by tectonic motion as supposed by Glover (pers. comm., 1997).

Increase in conductance has been observed near the 
Pliocene volcano Somló located in Fig. 1 at the crossing of the TCA3 and TCAh1 lines. This can be attributed to the volcanic heating which can promote graphitization of organic material. (See the theoretical calculation of the heating effect of a volcanic/intrusive body in the paper of Hvoždara and Brimich, 1991.)

The area of the TCA belongs to the Bakony-Drauzug (BDU) independent unit as supposed by Kázmér and Kovács (1985). At the western end of this BDU in the Gailtaler Alps, the Paleozoic graphitic formations (so-called "Altkristallin") outcrop and their very low resistivity and great anisotropy has directly been determined by audiomagnetotellurics (Ádám et al., 1990). These graphite seams are of same character, as those of the TCA may be and this information can help in the age determination of the conductive formation in Transdanubia, too.

\section{The Low Shear Stength (Low Viscosity) Graphite (and Fluid) and Seismicity}

It is worthy to mention that most of the earthquakes in the area of the TCA are anyhow connected to those three tectonic zones indicated by induction vectors (Fig. 11) and magnetotellurics (Fig. 16). Conductivity structure in the area of the Transdanubian earthquake activity has been studied in detail in the Mór graben (Ádám and Varga, 1990) and recently in the case of the Berhida earthquake in 1985 (Ádám and Zalai, 2000) (see MÓR and BERH areas in Fig. 1).

According to Meissner's (1986) formula there is a (qualitative) relation between the viscosity $(\zeta)$ (of graphite and fluid) and the attenuation $\left(Q^{-1}\right)$ of the seismic waves:

$$
\ln \zeta=4.4 \ln Q+22
$$

The validity of this relation for the TCA area has been confirmed by Zsíros (1985). He stated that the attenuation (in his formula $\alpha_{k}$ ) is higher in the area of the TCA than in the other part of Hungary (Fig. 17). He determined $\alpha_{k}\left[\mathrm{~km}^{-1}\right]$ by the formula:

$$
I_{k}=I_{o} \exp \left(-\alpha_{k} R_{k}\right)
$$

where

$I_{o}=$ epicentral intensity

$I_{k}=$ intensity of the $k$-th isoseism

$R_{k}=$ mean distance $[\mathrm{km}]$ of the $k$-th isoseism from the epicenter.

The phenomena supporting Zsíros' calculation were enumerated by Ádám (1994). Among them the distortion of the isoseismals, the attenuation in the TCA area of the earthquakes generated outside of Hungary's border etc. have been mentioned.

This hypothesis - about a relation of the attenuation of seismic waves to the low viscosity graphite (and fluid) accumulated in tectonic zones - has been studied using much greater data set. It has been concluded that the hypocenters of most earthquakes in the TCA area may be inside or below the graphitic conductor and the distribution of the hypocenters and the depth of the conductors is similar.

It is an interesting experience in connection of the depth of the TCA and earthquakes in this area: the depth of the conductor is shallower in the seismic active zones e.g. Mór region (Ádám and Varga, 1990) Bakonybél, etc.

Therefore the following hypothetical statements is worthy to be further studied:

- a common depth range of conductivity anomalies and of earthquakes hints at the graphitic (and fluid?) origin of the TCA, as such graphitic formations, accumulated in preformed zones can influence earthquakes with their low viscosity

- earthquakes are more severely attenuated in low viscosity graphitic blocks, therefore their devastation extends to much smaller areas

- earthquake mechanism starts at a lower level of stress accumulation, in the low viscosity graphitic bodies, therefore they can set an upper limit to earthquake magnitudes.

\section{Conclusion}

On the basis of the detailed study of about 300 magnetotelluric soundings, the main features of TCA can be summarized in the following way:

- The anomaly may consist of two main components: of a conducting layer and of conducting dikes supposedly in the tectonically weak zones (fractures faults/srike slips).

- Its material may be graphite (black shale), graphite film and fluid as concluded from its low resistivity, high conductance and high anisotropy. (The graphite has certainly been generated from organic material as the heating effect of the Pliocene basalt volcano Somló (Hvoždara and Brimich, 1991) can be recognized on TCA's horizontal extension and higher conductance.)

- The graphite has accumulated in the tectonically weak zones (fracture/fault/strike slip) due to shear precipitation and it forms conducting dikes.

- Three main tectonic lines (zones) could be distinguished. One is clearly connected to the known geology (Fig. 17), two other is quite new indication but could be supposed on the basis of the areal distribution of the earthquakes.

- These dikes border great resistive blocks enabling their motion by their low viscosity along the thrust sheet (detachment horizon) or in the strike slip zones.

- In the tectonically preformed zones a ductile state of the material may be caused by graphite (and fluid) and hence the stress accumulation is limited. Therefore earthquakes are generated at a lower level of the stress (slipping, creep) and so their intensity is less than without graphite. Due to the attenuation in the low viscosity graphite the devastation of the earthquakes can be observed in a smaller area.

- Concerning the three different inversion procedures used in this study it can be stated that all the three well 
localized the position of the dikes, but their shape has differently been determined. Rodi and Mackie (2001) $2 \mathrm{D}$ inversion code - similarly to the other 2D inversion codes-provides the smoothest model, without any sharp transition, that fits the data (Fig. 8(c)).

Acknowledgments. The author thanks for the financial support given by the Hungarian Science Foundation (OTKA, Joint GGRI and ELGI Project No T 029443) for this study. The author is indebted to Géza Varga for his close cooperation supplying ELGI's magnetotelluric data for reprocessing and interpretation together with GGRI's ones and to J. Rabi for his help in data treatment with GEOTOOLS. Thanks are due to Dr. Glover who helped to enlarge the dataset of Ádám's (1994) paper for illustration of the possible relation of the graphitic conductors and earthquake activity in the area of the TCA. The author strongly indebted to Dr. Alan Jones, Dr. Xavier Garcia and to an unknown referee who greatly helped with their advices and detailed proposals to improve the paper.

\section{References}

Ádám, A., Statistische Zusammanhänge zwischen elektrischer Leitfähigkeitsverteilung und Bruchtektonik in Transdanubien (Westungarn), Acta Geod. Geoph. Mont. Hung., 16, 97-113, 1981.

Ádám, A., Tectonic effects in the magnetotelluric field and their numerical modelling, Gerlands Beit. Geophysik, 96, 17-31, 1987.

Ádám, A., Transdanubian Conductivity Anomaly. Its geological and methodical significance, Értekezések, emlékezések. Akadémiai Kiadó, Budapest, 1-40, 1992 (in Hungarian).

Ádám, A., Is there any relation between the earthquakes and graphitic conductors in the upper crust? A hypothesis, Acta Geod. Geoph. Hung., 29, 149-159, 1994.

Ádám, A., Regional magnetotelluric (MT) anisotropy in the Pannonian Basin (Hungary), Acta Geod. Geoph. Hung., 31, 191-216, 1996.

Ádám, A. and G. Varga, Distortions of the electromagnetic field by shallow basins and by resistive outcrops, Phys. Earth Planet. Inter., 60, 80-88, 1990.

Ádám, A. and J. Verő, Ergebnisse der regionalen tellurischen Messungen in Ungarn, Acta Technica, 47, 761-773, 1964.

Ádám, A. and P. Zalai, Geoelectric model of the tectonics in the area of the Berhida earthquake, Magyar Geofizika, 41(2), 60-74, 2000 (in Hungarian).

Ádám, A., G. Duma, and J. Horváth, A new approach to the electrical conductivity anomalies in the Drauzug-Bakony geological unit, Phys. Earth Planet. Inter., 60, 155-162, 1990.

Arora, B. R. and A. Ádám, Anomalous directional behaviour of induction arrows above elongated conductive structures and its possible causes, Phys. Earth Planet. Inter, 74, 183-190, 1992.

Balázs, E., Rock analysis of the Paleozoic formations of the basement in the Western part of the Little Hungarian Plain, Kóolaj- és Földgázbányászat Tud. Közl., II, 38, 304-320, 1967 (in Hungarian).

Balla, Z., The main structural lines of the Hungarian Middle Range, Földtani Közlöny, 97, 265-277, 1967 (in Hungarian).

Berdichevsky, M. N., Marginal notes on magnetotellurics, Surveys in Geophysics, 20, 341-375, 1999.
Berdichevsky, M. N., V. I. Dmitriev, and E. E. Pozdnjakova, On two-dimensional interpretation of magnetotelluric soundings, Geophys. J. Int., 133, 585-606, 1998.

Constable, S. C., R. L. Parker, and C. G. Constable, Occam's inversion: a practical algorithm for generating smooth models from electromagnetic sounding data, Geophysics, 52, 289-300, 1987.

Eisel, M. and V. Haak, Macro-anisotropy of the electrical conductivity of the crust: a magnetotelluric study of the German Continental Deep Drilling site (KTB), Geophys. J. Int., 136, 109-122, 1999.

ELEKTB Group, KTB and the electrical conductivity of the crust, J. Geophys. Res., 102(B8), 18289-18306, 1997.

Groom, R. W. and R. C. Bailey, Decomposition of magnetotelluric impedance tensors in the presence of local three dimensional galvanic distortions, J. Geophys. Res., 94, 1913-1925, 1989.

Hvoždara, M. and L. Brimich, Thermoelastic deformation field due to magmatic bodies, Contr. Geophys. Inst. Slov. Acad. Sci., 21, 59-78, 1991.

Jankowski, J., V. Petr, J. Pěčová, and O. Praus, Geoelectric anomaly in Czechoslovak-Polish section of the Carpathians on the basis of geomagnetic and magnetotelluric soundings, Acta Geod. Geoph. Mont. Hung., 19, 81-91, 1984.

Kázmér, M. and S. Kovács, Permian-Palaeogene paleography along the eastern part of the Insubric-Periadriatic Lineament system: evidence for continental escape of the Drauzug-Bakony unit, Acta Geol. Hung., 28, 71-84, 1985.

Meissner, R., The continental crust. A geophysical approach, International Geophysics Series, 34, Academic Press, New York, 1986.

Nagy, Z., Advances in the combined interpretation of seismics with magnetotellurics, Geophys. Prospect., 44, 1041-1083, 1996.

Rodi, W. and R. L. Mackie, Nonlinear conjugate gradients algorithm for 2D magnetotelluric inversion, Geophysics, 66, 174-187, 2001.

Smith, J. T. and J. R. Booker, Rapid inversion of two- and three-dimensional magnetotelluric data, J. Geophys. Res., 96, 3905-3922, 1991.

Takács, E., Anomalous conductivity of the upper crust in the foreground of the Bakony Mountains, Acta Geod. Geoph. Mont. Hung., 3, 155-160, 1968.

Tátrallyay, M., On the interpretation of EM sounding curves by numerical modelling using the S.O.R. method, Acta Geod. Geoph. Mont. Hung., 12, 279-285, 1977.

Varga, G., Study of geological basic profiles. I. Report on telluric and MT measurements in 1979 in ELGI. Report, 1979 (in Hungarian).

Verö, J., On the determination of magnetotelluric impedance tensor, Acta Geod. Geoph. Mont. Hung., 7, 333-351, 1972.

Wallner, Á., The main features of the induction arrows in the area of the Transdanubian conductivity anomaly, Acta Geod. Geoph. Mont. Hung., 12, 145-150, 1977.

Wannamaker, P. A., G. W. Hohman, and S. H. Ward, Magnetotelluric responses of three-dimensional bodies in layered earths, Geophysics, 49, 1517-1533, 1984.

Zhamaletdinov, A. A., Graphite in the Earth's crust and electrical conductivity anomalies, Izvestiya Physics of the Solid Earth, 32 (4), 272-288 (Translated from Fizika Zemli, No. 4, 1996, 12-29), 1996.

Zsíros, T., An estimation of seismic hazard in Hungary, Gerlands Beitr. Geophys., 94, 111-122, 1985.

A. Ádám (e-mail: adam@ggki.hu) 